\title{
Relationship between Problematic Internet Use, Depression and Quality of Life Levels of Turkish University Students
}

\author{
Erkan Tekinarslan \\ Correspondence: Erkan Tekinarslan, Faculty of Education, No: 325, Abant Izzet Baysal University, Gölköy Campus, \\ 14280 Bolu, Turkey.
}

Received: December 26, 2016

Accepted: February 16, 2017 Online Published: February 20, 2017

doi:10.11114/jets.v5i3.2238

URL: https://doi.org/10.11114/jets.v5i3.2238

\begin{abstract}
The relationship between problematic Internet use (PIU), depression and quality of life levels of individuals is a growing concern in many societies. One of the main purposes of this study was to examine the relationships or correlations among PIU, depression and quality of life levels of Turkish undergraduate students. Furthermore, this study sought to investigate whether correlated variables; if any, simultaneously predicted students' quality of life levels on different domains of WHOQOL-BREF-TR in a significant manner. Moreover, this research examined whether some or any of study variables had a mediating effect in relationships between domains of WHOQOL-BREF-TR and other study variables. The data collected from 758 undergraduate student participants (431 female and 327 male) attending different faculties and colleges at a public university in Turkey. A demographical information form, the Beck Depression Inventory, the World Health Organization's Quality of Life-BREF (WHOQOL-BREF-TR) and Online Cognition Scale (OCS) were used to collect data from the undergraduate Turkish students. The results indicated that the students' PIU and depression levels were negatively associated with quality of life levels and positively associated with each other in a significant manner. Moreover, the results of hierarchical regression analysis revealed that PIU levels of the students on the diminished impulse control dimension partially mediated the relationships between depression and quality of life levels on all domains of WHOQOL-BREF-TR.
\end{abstract}

Keywords: problematic internet use, depression, quality of life, correlations, Turkish university students

\section{Introduction}

As a global network of networks, the Internet has become one of the essential information and communication mediums which can make important contributions to individuals' quality of life; and college students are not an exception in this regard. College students may benefit from the Internet for educational and academic purposes such as searching for information in electronic databases, communicating with teachers and classmates and participating in online courses and combined learning activities. Moreover, they may use the Internet for entertainment, leisure and social networking activities (Ghouth \& Salim, 2008; Maharana, Sethi \& Behera, 2010; Choudhary\& Dasgupta, 2014). College students' Internet use for leisure and social networking activities besides their educational and academic use of Internet has increased in recent years. However, the number of problematic or excessive Internet users among college students' has grown remarkably as well (Cheung, Lee \& Lee, 2013; Senol-Durak \& Durak, 2011; Kirschner, \& Karpinski, 2010; Frangos, Frangos, \& Sotiropoulos, 2010; Li, Wang, \& Wang, 2009; Chen \& Peng, 2008; Ceyhan, 2008). According to the related literature (e.g., Li, Zhang, Li, Zhen \& Wang, 2010; Kim, LaRose, \& Peng, 2009; Chen \& Peng, 2008; Kubey, Lavin, Barrows, 2001) excessive or problematic Internet use (PIU) causes problems in individuals' psychological and social lives and create difficulties in their work and school environments. For instance, a study conducted by Chen and Peng (2008) indicated that problematic or heavy Internet users are more likely to be depressed, physically ill, lonely, and introverted compared to light or moderate Internet users. On the other hand, un-problematic or moderate users had better relationships with administrative staff, better academic grades and higher learning satisfaction than problematic Internet users.

Additionally, prior studies (e.g., Ni, Yan, Chen \& Liu, 2009; Moreno, Jelenchick \& Breland, 2015) suggest that there might be significant associations between PIU and depression among college students. For instance, a recent study indicated that a positive relationship between depression and PIU for female U.S. college students. In addition to significant increases in risk for PIU among those reporting mild to moderate depression symptoms, findings indicated a dramatic increase in risk for PIU among those with the most severe depression (Moreno, Jelenchick \& Breland, 2015). 
Moreover, associations between quality of life and depression levels of individuals have been investigated in various studies (e.g., Çifci-Tekinarslan, 2013; Paro, Morales, Silva, Rezende, Pinto, Morales, Mendonça, \& Prado, 2010; Kim $\&$ Rew, 1994). These prior studies mostly exposed highly negative correlation between depression and quality of life, specifically indicating that individuals with higher depression levels usually have lower quality of life levels in comparison to others with lower depression levels. Furthermore, according to related literature (e.g., Liu \& Potenza, 2010; Black, Belsare \& Schlosser, 1999) PIU may lead to severe psychosocial and functional impairments. Thus, it is important to include quality of life measures of individuals with PIU in future studies (Liu \& Potenza, 2010). However, relationship between college students' PIU and quality of life levels have not been sufficiently investigated in previous empirical studies.

\subsection{Purpose of the Study}

The main purposes of the current study were divided in three-fold. The first purpose was to explore whether there were any significant correlations between the students' PIU, depression and quality of life levels on all domains of the World Health Organization's Quality of Life-BREF (WHOQOL-BREF-TR) (i.e., physical health, psychological health, social relationship, environment-tr). It was hypothesized that the students' quality of life levels on all domains are significantly correlated with their depression and PIU levels on all dimensions of PIU (i.e., social comfort, loneliness/ depression, diminished impulse control, distraction).

The second purpose was to examine whether correlated variables, if any, simultaneously predicted the students' quality of life levels on different domains of WHOQOL-BREF-TR in a significant manner. It was hypothesized that depression and diminished impulse control dimension of PIU which involves more severe problematic Internet uses (Davis, Flett \& Besser, 2002) will simultaneously predict the students' quality of life levels on all domains of WHOQOL-BREF-TR.

The third purpose was to investigate whether some or any of the study variables had a mediating effect in the relationships between domains of WHOQOL-BREF-TR and the other study variables. It was hypothesized that diminished impulse control dimension of PIU will partially mediate the relationships between depression and quality of life levels on all domains of WHOQOL-BREF-TR.

\section{Method}

\subsection{Participants}

The data collected from 758 undergraduate students [431 female (56.9\%) and 327 male (43.1\%)] studying in different faculties and colleges of a public university in West Black Sea Region of Turkey during 2015 spring semester. In addition, 188 students (24.8\%) were in first year, 254 students (33.6\%) were in second year, 148 students (19.5\%) were in third year, and 168 students $(22.1 \%)$ were in fourth year at school. Convenience sampling procedure, which involves participation of volunteers and existing groups, was applied to collect data (Gay, 1996). Data were collected after the research was approved by the research ethics committee at the related institution, with protocol No 2015/36.

\subsection{Instruments}

A demographical information form, the Beck Depression Inventory, WHOQOL-BREF-TR and Online Cognition Scale (OCS) were used to collect data from undergraduate Turkish students.

Demographical Information Form: The items on the questionnaire form for collect information about participant students' gender, year at school, Internet use durations, use of social networking tools (Facebook, Twitter, etc.), and Internet connection tools.

The Beck Depression Inventory (BDI): It was developed by Beck, Ward, Mendelson, Mock and Erbaugh (1961) to measure depression. The BDI scale with 21 items was adapted to Turkish by Hisli (1989) with 0.80 Cronbach's alpha reliability coefficient. The scale measures symptoms of depression related to emotional, cognitive, physical and motor functions. Each item of the BDI consists of four sentences on a Likert-type scale ranked from 0 (absence of a depressive symptom) to 3 (the highest degree of the symptom).

The World Health Organization's Quality of Life-BREF (WHOQOLBREF): The WHOQOL-BREF instrument, developed by the World Health Organization assesses quality of life. The instrument contains 26 items which measure four domains. Scores of the domains are scaled in a positive direction on a 5-point Likert-type scale, with higher scores indicating higher quality of life, and the scores range 4 to 20 . Additionally, the scores can be converted to a 0-100 scale. The domains of the WHOQOL-BREF are: (a) Physical health which is related to individuals' activities of daily living, dependence on medicinal substances and aids, energy and fatigue, mobility, pain and discomfort, sleep and rest and work capacity; (b) Psychological health which is related to the individual's bodily image and appearance, negative and positive feelings, self-esteem, spirituality, thinking, learning, memory and concentration; (c) Social relationship which is related to the individual's personal relationships, social support and sexual life; (d) Environment which is related to 
individuals' financial resources, freedom, physical safety and security, health and social care, home environment, opportunities for acquiring new information and skills, participation in and opportunities for recreation/leisure activities, physical environment and transport. The instrument was adapted by Eser, Fidaner, Fidaner, Eser, Elbi, and Göker (1999) into Turkish and during the process, an extra question was added to the Turkish version increasing the number of items to 27. Cronbach's alpha internal consistency coefficients $(\alpha)$ were Physical health 0.83 , Psychological health 0.66 , Social relationships 0.53 , Environment or National environment 0.73 respectively.

Online Cognition Scale (OCS): The OCS, as an assistive tool for multidimensional measure of PIU, developed and validated by Davis, Flett and Besser (2002). It contains 36 items on a seven-point Likert scale with scores for each item ranging from one (strongly disagree) to seven (strongly agree). There are four sub-scales of dimensions in OCS which are social comfort, loneliness/depression, diminished impulse control, and distraction. The validation study conducted by Davis, Flett and Besser (2002) indicated that Cronbach's alpha reliability coefficients $(\alpha)$ were $0.87,0.77,0.84$, and 0.81 respectively for social comfort, loneliness/depression, diminished impulse control and distraction dimensions and it was 0.94 for the entire OCS. The OCS was adapted to Turkish by Keser-Özcan and Buzlu (2005). Confirmatory factor analyses conducted by Keser-Özcan and Buzlu, (2005) exposed that the OCS in Turkish and original scale in English have consistent factorial structure. Additionally, reliability coefficients $(\alpha)$ were found to be $0.84,0.60,0.79$, and 0.73 respectively for social comfort, loneliness/depression, diminished impulse control and distraction dimensions and it was 0.91 for the entire scale in Turkish.

\subsection{Data Analyses}

Data analyses were carried out with the Statistical Packages for Social Sciences (SPSS) using descriptive statistics, bivariate correlations, multiple regression analyses and hierarchical regression analyses. Bivariate correlations were used to test the hypothesis that the students' quality of life levels on all domains of WHOQOL-BREF-TR (i.e., physical health, psychological health, social relationship, environment-tr) are significantly correlated with their depression and PIU levels on all dimensions (i.e., social comfort, loneliness/ depression, diminished impulse control, distraction). The multiple regression analyses were performed to test the hypothesis that depression and diminished impulse control dimension of PIU that includes more obsessive cognitions about the Internet use will simultaneously predict the students' quality of life levels on all domains of WHOQOL-BREF-TR. Additionally, hierarchical regression analyses were performed to test the hypothesis that diminished impulse control dimension of PIU will partially mediate the relationships between depression and quality of life levels on all dimensions of WHOQOL-BREF-TR.

Appropriateness of the data was examined prior to linear multiple regression analysis. Existence of a linear relationship was observed in scatterplots. In addition, normal P-P plot, partial regression graphics and histogram indicated no notable deviations from the normal distribution. Moreover, according to the Mahalanobis distance values (for $\chi^{2}=$ $20.517, \mathrm{p}=0.001$ ) calculated prior to the analyses, the data obtained from 21 participants presented extreme values. Thus, they were not included in the data analysis.

\section{Results}

\subsection{Descriptive Statistics}

According to the descriptive statistics in Table 1, most participant students use the Internet for 1 to 2 hours a day ( $\mathrm{n}=252$ ) and 3 to 5 hours per day $(n=249)$. Additionally, a considerable number of students $(n=157)$ use the Internet for more than 5 hours per day. Furthermore, a big majority of the students $(n=596)$ use social networking sites such as Facebook and Twitter. Moreover, most students connect to the Internet through smartphones $(n=556)$ or laptop computers $(\mathrm{n}=177)$.

\subsection{Correlations between PIU, Depression and Quality of Life Levels}

The results of bivariate correlations in Table 2 indicate significant associations between students' PIU levels on all dimensions (i.e., social comfort, loneliness/ depression, diminished impulse control and distraction), depression levels on BDI and quality of life levels on all domains of WHOQOL-BREF-TR (i.e., physical health, psychological health, social relationship, and environment-tr). In addition, the findings showed that while there were positive correlations between students' PIU and depression levels, relationship between students' PIU and quality of life levels were negatively associated. Similarly, relationship between students' depression and quality of life levels were also negatively associated. 
Table 1. Descriptive statistics

\begin{tabular}{|c|c|c|c|}
\hline Groups & & $\mathrm{n}$ & $\%$ \\
\hline \multirow{5}{*}{ Internet Use Duration } & $1-5$ hours a month & 23 & 3 \\
\hline & 1-5 hours a week & 76 & 10 \\
\hline & 1-2 hours a day & 253 & 33.4 \\
\hline & 3-5 hours a day & 249 & 32.8 \\
\hline & More than 5 hours a day & 157 & 20.7 \\
\hline \multirow{2}{*}{$\begin{array}{lll}\text { Use of Social Networking Tools } \\
\text { (Facebook, Twitter, etc.) }\end{array}$} & Yes & 596 & 78.6 \\
\hline & No & 162 & 21.4 \\
\hline \multirow{4}{*}{ Internet Connection Tools } & Smartphone & 556 & 73.4 \\
\hline & Tablet PC & 13 & 1.7 \\
\hline & Laptop & 177 & 23.4 \\
\hline & Desktop & 12 & 1.6 \\
\hline
\end{tabular}

Table 2. Correlations between dimensions of PIU, WHOQOL-BREF-TR and BDI

\begin{tabular}{|c|c|c|c|c|c|c|c|c|c|c|}
\hline & \multirow[b]{2}{*}{ Dimensions } & \multicolumn{4}{|c|}{ PIU Dimensions } & \multirow{2}{*}{$\begin{array}{c}\text { BDI } \\
5\end{array}$} & \multicolumn{4}{|c|}{ WHOQOL-BREF-TR Domains } \\
\hline & & \multirow{2}{*}{$\frac{1}{1}$} & 2 & \multirow[t]{2}{*}{3} & \multirow[t]{2}{*}{4} & & 6 & 7 & 8 & 9 \\
\hline & 1. Social Comfort & & & & & & & & & \\
\hline & 2.Loneliness/depression & $.724 * *$ & 1 & & & & & & & \\
\hline 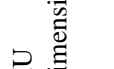 & $\begin{array}{l}\text { 3. Diminished } \\
\text { Impulse Control }\end{array}$ & $.700 * *$ & $757 * *$ & 1 & & & & & & \\
\hline $\bar{a} \ddot{a}$ & 4. Distraction & $.634 * *$ & $.669 * *$ & $.634 * *$ & 1 & & & & & \\
\hline 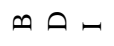 & 5. Depression-BDE & $.189 * *$ & $.212 * *$ & $.247 * *$ & $.311 * *$ & 1 & & & & \\
\hline & 6. Physical health & $-.082 *$ & $-.130 * *$ & $-.187 * *$ & $-.132 * *$ & $-.388 * *$ & 1 & & & \\
\hline & 7. Psychological health & $-.103 * *$ & $-.165 * *$ & $-.231 * *$ & $-.224 * *$ & $-.565 * *$ & $.556 * *$ & 1 & & \\
\hline ○ & 8. Social relationship & $-.086^{*}$ & $-.104 * *$ & $-.164 * *$ & $-.128 * *$ & $-.301 * *$ & $.405 * *$ & $.528 * *$ & 1 & \\
\hline$\stackrel{\frac{\pi}{3}}{3}$ & 9. Environment-tr & $-.096 * *$ & $-.163 * *$ & $-.217 * *$ & $-.187 * *$ & $-.400 * *$ & $.458 * *$ & $.576^{* *}$ & $.508 * *$ & 1 \\
\hline & Mean & 27.44 & 12.61 & 23.35 & 19.04 & 33.04 & 14.99 & 14.44 & 13.96 & 13.70 \\
\hline & SD & 11.65 & 6.04 & 9.45 & 8.59 & 8.64 & 2.24 & 2.43 & 2.95 & 2.05 \\
\hline
\end{tabular}

**Correlation is significant at the 0.01 level (2-tailed)

*Correlation is significant at the 0.05 level (2-tailed).

However, findings revealed that correlations between students' PIU levels on all dimensions and their quality of life levels on all domains of WHOQOL-BREF-TR were lower than the correlations between students' PIU and depression levels on BDI. Moreover, results showed that correlations between students' PIU levels on all dimensions and their depression levels were lower than the correlations between students' quality of life levels on domains of WHOQOLBREF-TR and their depressions levels on BDI. As a result, findings revealed higher negative correlations between students' depression levels and quality of life levels on the domains of WHOQOL-BREF-TR in comparison to negative correlations between students' PIU and quality of life levels.

\subsection{Results of Regression Analysis}

Table 3 displays the results of the multiple regression analyses including unstandardized coefficients (B), standardized coefficients $(\beta), t$ and $p$ values. The regression coefficients indicated that factors which significantly predicted students' quality of life levels on the physical health domain of WHOQOL-BREF-TR were their depression levels $(\beta=-.374 ; \mathrm{t}=$ $-10.65, \mathrm{p}<.01)$ and PIU levels on the dimension of diminished impulse control $(\beta=-.184 ; \mathrm{t}=-3.307, \mathrm{p}<.01)$ in a simultaneous manner.

Table 3. The results of multiple regression analysis related to the prediction of quality of life on the domains of WHOQOL-BREF-TR

\begin{tabular}{|c|c|c|c|c|c|c|c|c|c|c|c|c|}
\hline & \multicolumn{12}{|c|}{ Domains of WHOQOL-BREF-TR } \\
\hline & \multicolumn{3}{|c|}{ Physical health } & \multicolumn{3}{|c|}{ Psychological health } & \multicolumn{3}{|c|}{ Social relationship } & \multicolumn{3}{|c|}{ Environment-tr } \\
\hline & B & $\beta$ & $t$ & B & $\beta$ & $t$ & B & $\beta$ & $t$ & B & $\beta$ & $t$ \\
\hline Constant & 18.52 & & $57.3 *$ & 19.87 & & $63.43 *$ & 17.68 & & $40.03^{*}$ & 17.08 & & $58.35^{*}$ \\
\hline Depression-BDI & -.097 & -.374 & $-10.65 *$ & -.152 & -.538 & $-17.18 *$ & -.096 & -.281 & $-7.70 *$ & -.087 & -.368 & $-10.58 *$ \\
\hline Social Comfort -PIU & .018 & .096 & 1.83 & .030 & .143 & $3.06^{*}$ & .012 & .048 & .874 & .025 & .140 & $2.68 *$ \\
\hline $\begin{array}{l}\text { Loneliness/ } \\
\text { depression-PIU }\end{array}$ & -.007 & -.019 & -.321 & .001 & .002 & .032 & .018 & .037 & .620 & -.010 & -.031 & -.533 \\
\hline $\begin{array}{l}\text { Diminished Impulse } \\
\text { Control- PIU }\end{array}$ & -.044 & -.184 & $-3.307^{*}$ & -.046 & -.178 & $-3.59 *$ & -.051 & -.164 & $-2.83 *$ & -.041 & -.190 & $-3.45^{*}$ \\
\hline $\begin{array}{l}\text { Distraction-PIU } \\
\text { Adjusted } \mathrm{R}^{2}\end{array}$ & $\begin{array}{l}.015 \\
.161 * \\
\end{array}$ & .057 & .1 .149 & $\begin{array}{l}-.009 \\
.333 *\end{array}$ & -.032 & -.72 & $\begin{array}{l}.004 \\
.096 *\end{array}$ & .012 & .228 & $\begin{array}{l}-.004 \\
.178^{*}\end{array}$ & -.017 & .-.339 \\
\hline
\end{tabular}

In addition, variables that significantly predicted students' quality of life levels on psychological health domain of 
WHOQOL-BREF-TR were their depression levels $(\beta=-.538 ; \mathrm{t}=-17.18, \mathrm{p}<.01)$, PIU levels on dimensions of social comfort $(\beta=.143 ; \mathrm{t}=3.06, \mathrm{p}<.05)$ and diminished impulse control $(\beta=-.178 ; \mathrm{t}=-3.59, \mathrm{p}<.01)$. Additionally, the regression coefficients indicated that variables which significantly influenced the quality of life levels of students on the social relationship domain of WHOQOL-BREF-TR were their depression levels $(\beta=-.281 ; \mathrm{t}=-7.70, \mathrm{p}<.01)$ and PIU levels on the dimension of diminished impulse control $(\beta=-.164 ; \mathrm{t}=-2.83, \mathrm{p}<.01)$ in a simultaneous manner. Furthermore, variables that significantly predicted students' quality of life levels on environment-tr domain of WHOQOL-BREF-TR were their depression levels $(\beta=-.368 ; \mathrm{t}=-10.58, \mathrm{p}<.01)$, PIU levels on dimensions of social $\operatorname{comfort}(\beta=.140 ; \mathrm{t}=2.68, \mathrm{p}<.01)$ and diminished impulse control $(\beta=-.190 ; \mathrm{t}=-3.45, \mathrm{p}<.01)$ in a simultaneous manner.

As a result, based on the regression coefficients, findings of multiple regression analyses revealed that depression and PIU levels of students on diminished impulse control were the first two predictors of quality of life levels on all domains of WHOQOL-BREF-TR. In simple words, the biggest predictor of students' quality of life levels on all domains was their depression levels followed by PIU levels on diminished impulse control dimension.

3.4 Mediational Role of Diminished Impulse Control Dimension of PIU in the Relationship between Depression and Quality of Life

Hierarchical regression analysis was conducted to examine whether the diminished impulse control dimension of PIU had a mediating effect in the relationship between students' depression and quality of life levels of on the domains of WHOQOL-BREF-TR by following Baron and Kenny's (1986) recommendations: In the first step, a significant correlation between the independent variable and the presumed mediator is required. In the second step, a significant correlation between the presumed mediator and the dependent variable is required. In the third step, when the predictor and the presumed mediator simultaneously predict the dependent variable, if the previously significant relationship between the independent and dependent variable is no longer significant it is named as fully mediation or if the relationship decreases it is named as partial mediation.

Firstly, as it was previously indicated in Table 2, it was verified that PIU levels of students on diminished impulse control dimension and their depression levels on BDI were positively correlated $(\mathrm{r}=.247)$. Then, the regression analysis revealed that students' PIU levels on diminished impulse control dimension were also negatively associated with their quality of life levels on all domains of WHOQOL-BREF-TR in a significant manner respectively on physical health $\left(\beta=-.187 ; \mathrm{t}=-5.226, \mathrm{p}<.01 ; \mathrm{R}^{2}=.157\right)$, psychological health $\left(\beta=-.231 ; \mathrm{t}=-6522, \mathrm{p}<.01 ; \mathrm{R}^{2}=.326\right)$ social relationship $(\beta=$ $\left.-.164 ; \mathrm{t}=-4.573, \mathrm{p}<.01 ; \mathrm{R}^{2=} .097\right)$ and environment $-\operatorname{tr}\left(\beta=-.217 ; \mathrm{t}=-6.12, \mathrm{p}<.01 ; \mathrm{R}^{2}=.173\right)$.

After that, the regression results showed that students' depression levels were negatively correlated with their quality of life levels on all domains of WHOQOL-BREF-TR in a significant manner respectively on physical health $(\beta=-.388 ; \mathrm{t}=$ $\left.-11.574, \mathrm{p}<.01 ; \mathrm{R}^{2}=.157\right)$, psychological health $\left(\beta=-.565 ; \mathrm{t}=-18.825, \mathrm{p}<.01 ; \mathrm{R}^{2}=.326\right)$, social relationship $(\beta=-.301 ; \mathrm{t}=$ $\left.-8.678, \mathrm{p}<.01 ; \mathrm{R}^{2}=.097\right)$ and environment- $\operatorname{tr}\left(\beta=-.400 ; \mathrm{t}=-12.007, \mathrm{p}<.01 ; \mathrm{R}^{2}=.173\right)$.

However, as indicated in Figure 1, when depression and PIU levels on diminished impulse control dimension were taken together in the regression analysis, the significance of the relationships between the students' depression and quality of levels on domains of WHOQOL-BREF-TR were decreased respectively on physical health (from $\beta=-.388$ to $\beta=-.364$ ), psychological health (from $\beta=-.565$ to $\beta=-.541$ ) social relationship (from $\beta=-.301$ to $\beta=-.277$ ), and environment-tr (from $\beta=-.400$ to $\beta=-.369$ ). Yet, the relationships between students' depression and quality of life levels on all domains of WHOQOL-BREF-TR were significant. According to Baron and Kenny (1986), these findings disclose that students' PIU levels on the diminished impulse control dimension partially explain or mediate the relationships between the depression and quality of life levels on all domains of WHOQOL-BREF-TR. 


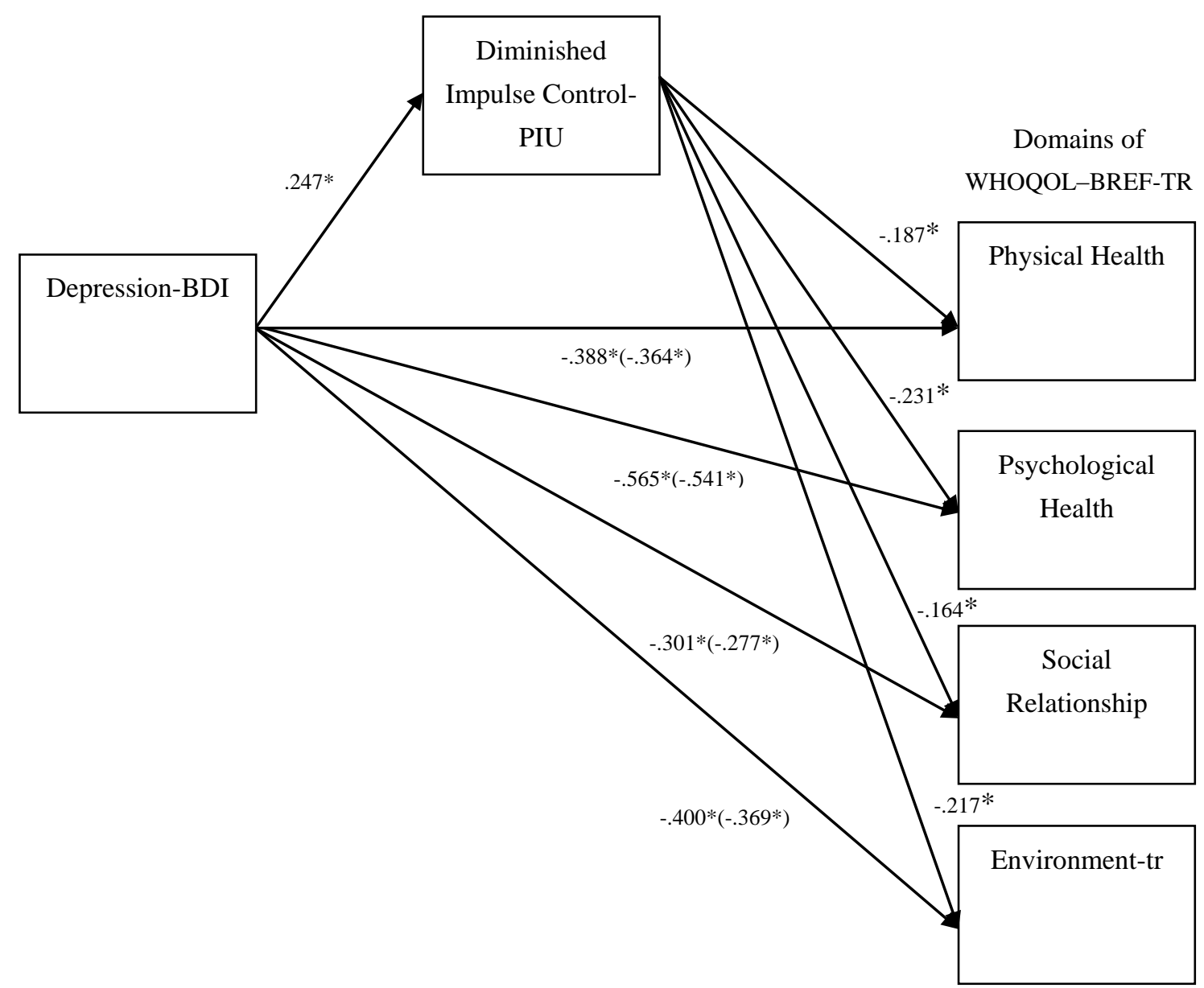

Figure 1. The hierarchical regression coefficients for the relationship between scores on the domains of quality of life (WHOQOL-BREF-TR) and depression as mediated by diminished impulse control dimension of PIU. The regression coefficients between depression and domains of WHOQOL-BREF-TR controlling for diminished impulse control dimension of PIU, are in parentheses. * $\mathrm{p}<.01$

\section{Discussion}

One of the purposes of this study was to investigate the relationships between students' PIU, depression and quality of life levels. The results of bivariate correlations indicated that the students' quality of life levels on all domains of quality of life were significantly correlated with their depression and PIU levels on all dimensions, as consistent with the first hypothesis. There were positive correlations between students' depression and PIU levels. On the other hand, there were negative correlations between students' PIU and quality of life levels, and between their depression and quality of life levels. In addition, these findings are also supported by the related literature (e.g., Ni, Yan, Chen \& Liu, 2009; Moreno, Jelenchick \& Breland, 2015) which revealed that there are positive associations between PIU and depression levels of the college students. Besides, the findings of this study are consistent with the prior studies (i.e., Çifci-Tekinarslan, 2013; Angermeyer, Holzinger, Matschinger, Stengler-Wenzke, 2002) which indicated that depression may have negative effects on individuals' quality of life.

Moreover, multiple regression analyses were performed to examine whether students' quality of life levels were predicted simultaneously by their PIU and depression levels in a significant manner. Based on the larger regression coefficients, the biggest predictor of quality of life levels of the students on all domains is their depression levels followed by their PIU levels on diminished impulse control dimension. Therefore, the second hypothesis was supported largely by the results of multiple regression analyses.

Furthermore, this study examined whether students' PIU level on diminished impulse control dimension had a mediating effect in relationships between depression and quality of life on all domains of WHOQOL-BREF-TR. As hypothesized, the students' PIU levels on the diminished impulse control dimension partially explained or mediated the relationships between depression and quality of life levels on all the domains, based on the results of hierarchical regression analysis. According to Davis et al. (2002), diminished impulse control is clearly an indicator of more severe PIU which involves risk taking and dangerous behaviors such as online gambling, pornography and engaging illegal 
activities online (e.g., sending viruses). In addition, related literature (e.g., Yau, Potenza \& White, 2013; Anderson, 2000; Sanders, Field, Diego \& Kaplan, 2000; Willoughby, 2008) discusses that diminished control over the Internet use may be problematic and have negative impacts on daily functions, family relationships and emotional stability. Therefore, the partial explanation or mediation of diminished impulse control dimension of PIU for the relationship between depression and quality of life levels on all the domains might be related to its involvement with more severe problematic Internet uses which are positively associated with depression and negatively associated with the quality of life of individuals. As a result, by considering the results of this study and the related literature (e.g., Davis et al., 2002; Yau, Potenza \& White, 2013), it can be argued that students with higher PIU levels on the diminished impulse control dimension are more likely to have higher depression levels and lower quality of life compared to students without or lower PIU levels.

\subsection{Limitations of the Study}

There are several limitations that merit attention. First, the participant students were not randomly selected, and hence, the results obtained in the study cannot be generalized to all Turkish university students with depression and PIU. Second, BDI is a valid and reliable measure of symptoms of depression related to emotional, cognitive, physical and motor functions (Beck, et al., 1961) and it is designed as a screening device rather than a diagnostic tool for specific types of depression. Therefore, more detailed diagnoses using the structured or semi-structured clinical measure or interview for depression may be applied to identify types of depression (e.g., melancholia, psychotic depression, etc.) in need of specialized treatment for the symptoms and to improve the quality of life levels of the students. Similarly, although OCS in a valid and reliable assistive tool for the multidimensional measure of PIU, particularly the diminished impulse control dimension related to the Internet use (Davis et al., 2002), it does not assist in diagnosis of other types and symptoms of impulse control disorder. Thus, more detailed diagnoses applying a structured or semi-structured clinical measure for impulse control disorder can be required to detect if there are other types and symptoms of the disorder in need of specialized treatment and to increase the quality of life levels of the students.

\section{Conclusion}

The findings of this study indicates positive relationships between depressions and PIU levels of the Turkish university students. However, the findings show negative relationships between the students' quality of life and depression levels, and between their quality of life and PIU levels. Moreover, the results of multiple regression analyses revealed that depression is the biggest predictor of quality of life levels of the students followed by their PIU levels on diminished impulse control dimension. Furthermore, according to results of hierarchical regression analysis, the students' PIU levels on the diminished impulse control dimension partially mediated the relationships between depression and quality of life levels on all the domains.

As a result, based on the findings, it can be suggested that the students can be screened routinely for severe PIU, particularly on diminished impulse control dimension, as part of their health care visits. The students with severe PIU can be provided to professional counseling services to prevent them from the negative effects of PIU in their school, psychological and social lives. Furthermore, screening for depression may be applied in need of specialized treatment among the students with notable diminished impulse control disorder related to the PIU, in order to improve their quality of life.

\section{References}

Anderson, K. J. (2000). Internet use among college students: An exploratory study. Journal of American College Health, 50(1), 21-26. https://doi.org/10.1080/07448480109595707

Angermeyer, M. C., Holzinger, A., Matschinger, H., \& Stengler-Wenzke, K. (2002). Depression and quality of life: Results of a follow-up study. The International Journal of Social Psychiatry, 48, 189-199. https://doi.org/10.1177/002076402128783235

Baron, R. M., \& Kenny, D. A. (1986). Moderator-mediator variables distinction in social psychological research: Conceptual, strategic, and statistical considerations. Journal of Personality and Social Psychology, 6, 1173-1182. https://doi.org/10.1037/0022-3514.51.6.1173

Beck, A. T., Ward, C. H., Mendelson, M., Mock, J., \& Erbaugh, J. (1961). An inventory for measuring depression. Archives General Psychiatry, 4, 561-571. https://doi.org/10.1001/archpsyc.1961.01710120031004

Black, D. W., Belsare, G., \& Schlosser, S. (1999). Clinical features, psychiatric comorbidity and health-related quality of life in persons reporting compulsive computer use behavior. Journal of Clinical Psychiatry, 60(12), 839-844. https://doi.org/10.4088/JCP.v60n1206

Ceyhan, A. A. (2008). Predictors of problematic Internet use on Turkish university students. Cyber Psychology \& 
Behavior, 11(3), 363-366. https://doi.org/10.1089/cpb.2007.0112

Chen, Y. F., \& Peng, S. S. (2008). University students' internet use and its relationships with academic performance, interpersonal relationships, psychosocial adjustment, and self-evaluation. Cyber Psychology \& Behavior, 11(4), 467-469. https://doi.org/10.1089/cpb.2007.0128

Cheung, C. M. K., Lee, Z. W. Y., \& Lee, M. K. O. (2013). Understanding Compulsive Use Of Facebook Through The Reinforcement Processes". Proceedings of the 21st European Conference on Information Systems (ECIS, 2013). ECIS 2013 Completed Research. Paper 22. Retrieved on February 16, 2016 from http://aisel.aisnet.org/ecis2013_cr/22

Choudhary, S., \& Dasgupta, P. (2014). Internet usage pattern and searching behaviour: A users' study of Assam University, Silchar. Asian Journal of Multidisciplinary Studies, 2(12), Retrieved February, 10, 2016, from http://www.ajms.co.in/sites/ajms2015/index.php/ajms/article/view/800/602

Çifci-Tekinarslan, I. (2013). A comparison study of depression and quality of life in Turkish mothers of children with down syndrome, Cerebral palsy, and autism spectrum disorder. Psychological Reports, 112 (1), 266-287. https://doi.org/10.2466/21.02.15.PR0.112.1.266-287

Davis, R. A., Flett, G. L., \& Besser, A. (2002). Validation of a new scale for measuring problematic internet use: Implications for pre-employment screening. CyberPsychology \& Behavior, 5(4), 331-345. https://doi.org/10.1089/109493102760275581

Eser, E., Fidaner, H., Fidaner, C., Eser, S. Y., Elbi, H., \& Göker, E. (1999). Psychometric features of the WHOQOL-100 and WHOQOL-BREEF. 3P Journal, 7, 23-40.

Frangos, C. C., \& Sotiropoulos, I. (2010). Problematic Internet use among Greek university students: An ordinal logistic regression with risk factors of negative psychological beliefs, pornographic sites, and online games. Cyber psychology, Behavior, and Social Networking. https://doi.org/10.1089/cyber.2009.0306

Gay, L. R. (1996). Educational research: Competencies for analysis and application. Englewood Cliffs, NJ:Prentice-Hall, Inc.

Ghouth, B., \& Salim, A. (2008). Using Computer and Internet for Medical Literature Searching Among Medical Students in Hadramout University, Yemen. Online Journal of Health and Allied Sciences, 7(1), Retrieved on February 10, 2016, http://cogprints.org/6087/1/2008-1-6.pdf

Hisli, N. (1989). Reliability and validity of Beck Depression Inventory for university students, Journal of Psychology, 7(23), 3-13.

Keser-Özcan, N., \& Buzlu, S. (2005). Problemli İnternet kullanımı belirlemede yardımcı bir araç: İnternette bilişsel durum ölçeğinin üniversite öğrencilerinde geçerlik ve güvenirliği. Journal of Dependence, 6 (1), 19-26.

Kim, J., LaRose, R., \& Peng, W. (2009). Loneliness as the cause and the effect of problematic Internet Use: The relationship between Internet use and psychological well-being. Cyber Psychology \& Behavior, 12(4), 451-455. https://doi.org/10.1089/cpb.2008.0327

Kim, S., \& Rew, L. (1994). Ethnic identity, role integration, quality of life, and depression in Korean-American women. Archives of Psychiatric Nursing, 8(6), 348-356. https://doi.org/10.1016/0883-9417(94)90003-5

Kirschner, P. A., \& Karpinski, A. C. (2010). Facebook and academic performance. Computers in Human Behavior, 26(6), 1237-1245. https://doi.org/10.1016/j.chb.2010.03.024

Kubey, R. W., Lavin, M. J., \& Barrows, J. R. (2001). Internet use and collegiate academic performance decrements: Early findings. Journal of Communication, 51, 366-382. https://doi.org/10.1111/j.1460-2466.2001.tb02885.x

Li, D., Zhang, W., Li, X., Zhen, S., \& Wang, Y. (2010). Stressful life events and problematic Internet use by adolescent females and males: A mediated moderation model. Computers in Human Behavior. https://doi.org/10.1016/j.chb.2010.03.031

Li, H., Wang, J., \& Wang, L. (2009). A survey on the generalized problematic internet use in Chinese college students and its relations to stressful life events and coping style. International Journal of Mental Health and Addiction, 7(2), 333-346.

Liu, T., \& Potenza, M. N. (2010). Problematic Internet Use: Clinical Aspects. In E. Aboujaoude and L. M. Koran (Eds.), Impulse control disorders (pp. 167-181). Cambridge: Cambridge University Press. https://doi.org/10.1017/cbo9780511711930.016

Maharana, B., Sethi, B. B., \& Behera, S. (2010). Use of internet and e-resources by the students of business 
management: A survey of P. G. students of business administration, Sambalpur University, India. International Journal of Library and Information Science, 2(3), 45-53. Retrieved on February 10, 2016, from http://www.academicjournals.org/article/article1379414301_Maharana\%20et\%20al.pdf

Moreno, M. A., Jelenchick, L. A., \& Breland, D. J. (2015). Exploring depression and problematic internet use among college females: A multisite study. Computers in Human Behavior, 49, 601-607. https://doi.org/10.1016/j.chb.2015.03.033

Ni, X. L., Yan, H., Chen, S. L., \& Liu, Z. W. (2009). Factors influencing internet addiction in a sample of freshmen university students in China. Cyber Psychology and Behavior, 12(3), 327-330. https://doi.org/10.1089/cpb.2008.0321

Paro, H. B., Morales, N. M., Silva, C. H., Rezende, C. H., Pinto, R. M., Morales, R. R., ... Prado, M. M. (2010). Health-related quality of life of medical students. Medical Education, 44(3), 227-235. https://doi.org/10.1111/j.1365-2923.2009.03587.x

Sanders, C. E., Field, T. M., Diego, M., \& Kaplan, M. (2000). The relationship of Internet use to depression and social isolation among adolescents. Adolescence, 35, 237-242

Senol-Durak, E., \& Durak, M. (2011). The mediator roles of life satisfaction and self-esteem between the affective components of psychological well-being and the cognitive symptoms of problematic internet use. Social Indicators Research, 103(1), 23-32. https://doi.org/10.1007/s11205-010-9694-4

Willoughby, T. (2008). A short-term longitudinal study of Internet and computer game use by adolescent boys and girls: Prevalence, frequency of use, and psychosocial predictors. Developmental Psychology, 44(1), 195-204. https://doi.org/10.1037/0012-1649.44.1.195

Yau, Y. H. C., Potenza, M. N., \& White, M. A. (2013). Problematic Internet use, mental health and impulse control in an online survey of adults. Journal of Behavioral Addictions, 2(2), 72-81. https://doi.org/10.1556/JBA.1.2012.015

\section{Copyrights}

Copyright for this article is retained by the author(s), with first publication rights granted to the journal.

This is an open-access article distributed under the terms and conditions of the Creative Commons Attribution license which permits unrestricted use, distribution, and reproduction in any medium, provided the original work is properly cited. 